TITLE:

\title{
For whom the male waves: four types of claw-waving display and their audiences in the fiddler crab, Uca lactea
}

$\operatorname{AUTHOR}(S)$ :

Muramatsu, Daisuke

CITATION:

Muramatsu, Daisuke. For whom the male waves: four types of claw-waving display and their audiences in the fiddler crab, Uca lactea. Journal of Ethology 2011, 29(1): 3-8

\section{ISSUE DATE:}

2011-01-01

URL:

http://hdl.handle.net/2433/197373

\section{RIGHT:}

The final publication is available at Springer via http://dx.doi.org/10.1007/s10164-0100216-2; This is not the published version. Please cite only the published version.; この論文 は出版社版でありません。引用の際には出版社版をご確認ご利用ください。 
For whom the male waves: Four types of claw-waving display and their audiences in the fiddler crab, Uca lactea

\section{DAISUKE MURAMATSU}

Department of Zoology, Graduate School of Science, Kyoto University

[20] pages

[0] tables

[1] figures

[4] video figures

Department of Zoology, Graduate School of Science, Kyoto University Sakyo-ku, Kyoto, 606-8502, JAPAN

Tel: +81-75-753-4099

Fax: $+81-75-753-4113$

E-mail: muramatsu@ethol.zool.kyoto-u.ac.jp 


\section{Abstract}

Some animals are known to use several different signals which convey different messages. In the fiddler crab Uca lactea, I found that males performed at least four types of claw-waving display: lateral-circular, lateral-flick, rapid-vertical, and circular waving. The major audiences and the seasonal occurrence patterns of the displays differed among waving types. Lateral-circular waving (combinations of slow lateral extension, quick flexion, and circumduction of the major claw) was mostly performed to female audiences and was observed frequently in the breeding season. Lateral-flick waving (quick lateral abduction to the audience) was frequently performed to neighbor residents but rarely performed to females in the breeding season. Rapid vertical waving (rapid dorso-ventral protraction and retraction) was observed throughout the observation period and was most frequently performed to burrowless males. Circular waving (simple circumduction) was frequently observed prior to the breeding season and had no obvious audience in most cases. The results showed that males performed different types of claw-waving in different contexts. Males may have needed to use several different types of waving in order to transmit different messages. Digital video images relating to this article are available at http//www.momop.com/showdetail-e.php?movieid=momo091127ul01a, http//www.momop.com/showdetail-e.php?movieid=momo091127ul02a, http//www.momop.com/showdetail-e.php?movieid=momo091127ul03a, http//www.momop.com/showdetail-e.php?movieid=momo091127ul04a. 
Key words: multiple signals; waving; display; fiddler crab; Uca lactea

\section{Introduction}

Animals sometimes use several different signals within a species (Borgia 1995;

Coleman et al. 2004; Elias et al. 2005; Chaine \& Lyon 2008). These multiple signals may provide the same information (backup/redundant signal) that allows for an increased accuracy of receiver response; or provide different information (multiple messages) such as species identity, location, and various aspects of individual quality (Candolin 2003; Hebets \& Papaj 2005). Backup signals are predicted to be similar in their occurrence patterns, while signals involved in multiple messages would be used in different contexts, and therefore have different occurrence patterns (Hebets \& Papaj 2005). The majority of studies have found multiple signals to be uncorrelated, suggesting that backup signals are less common than multiple messages (Candolin 2003).

Male fiddler crabs (Uca) have an enlarged claw that is used for claw-waving display. The function of waving has been somewhat contentious, but is mainly considered to be courtship (e.g., Yamaguchi 1983, 2001a; Burford et al. 2000; Pope 2000a, b; Christy et al. 2001, 2002) and/or aggression (e.g., Crane 1958; Salmon 1965; Zeil et al. 2006). In several species, males perform two types of display, vertical- and lateral-waving (Severinghaus \& Lin 1990; Christy et al. 2001, 2002; How et al 2007). According to my personal observations, males of $U$. lactea have more than two types of distinct claw-waving, which appear to be 
used in different contexts. In this article, I describe these several types of clawwaving, their audiences, and seasonal fluctuation patterns of their occurrence. If each type of waving conveys a different message, all the waving displays should have different tendencies regarding the audiences, and different types of waving should be performed in different phases of the breeding cycle. Moreover, I expect these types of claw-waving associate with different functions, and the results of the present study contribute to estimate each function. Courtship displays, for example, would be performed frequently in the breeding season toward female audiences.

\section{Materials and methods}

All observations were carried out in a dense colony of $U$. lactea, including approximately $1 \%$ of Scopimera globosa, which was located on an intertidal mudflat in the estuary of the Hachiman River, Kagoshima, Japan ( $31^{\circ} 22^{\prime} \mathrm{N}$, $\left.130^{\circ} 32^{\prime} \mathrm{E}\right)$. Crabs emerged from their burrows and were active on the mudflat surface during diurnal low tides. Observations were carried out on 2 to 3 days during spring tides from May to November 2001, except for the days with heavy rain. The crabs' breeding season spans from early June to the end of August (Yamaguchi 2001b), and so my study period included both breeding and nonbreeding times in the cycle.

Six observation points were established at the study site. These points were established in line, parallel to the river, and were spaced three meters from 
each other. Each point was marked with a 90-cm-long, 5-mm-diameter wooden pole, which was inserted vertically into the sediment, leaving approximately 5 $\mathrm{cm}$ above the surface. Each day, two observation points were chosen in random order, and at each point, I observed 10 burrows occupied by males, beginning with the burrow closest to the pole. The same point was not chosen more than once in a single spring tide. Behavioral observations of focal males were made within 2 hours before and after the peak of low tide because crabs were not active at the beginning and the end of the habitat exposure.

Claw-waving of each focal male was observed for 1 minute. To avoid disturbing the crabs' behavior, I remained stationary during the observation. Prior to the observation, I waited 10 minutes at each observation point to ensure that crabs emerged and resumed normal behavior. Crabs often entered their burrow in response to my approach, but they usually re-emerged from their burrow within a few minutes. All waving behaviors and their duration were recorded using a SONY ICD-R100 voice recorder. Displays were often directed to nearby conspecifics. In such cases, I recorded the sex of the audience and whether the audience had its own burrow. When I did not recognize an obvious audience, the display was counted as to "unknown audience". Altogether I recorded five types of audience: resident male (male that had its own burrow), resident female, burrowless male (male that did not have its own burrow), burrowless female and unknown audience.

Displays that had different motions of the major claw, walking legs, and body elevation were separately counted and averaged per spring tide. Within each type of display, Wilcoxon's signed rank test was applied to compare the 
frequencies of claw-waving toward male and female audiences. The frequencies of claw-waving toward resident and burrowless audiences were also compared using Wilcoxon's signed rank test.

\section{Results}

Four typical motions of claw-waving were recognized: lateral-circular, lateralflick, rapid-vertical, and circular waving (Fig. 1, 2, 3, 4, respectively). Their definitions, audiences, and seasonal fluctuation patterns are described below.

(a) Lateral-circular waving (Fig. 1)

The major claw was extended laterally, and raised and lowered once or twice while the crab walked toward the side of its minor claw, and then the major claw was circularly swung down to the front (phase A). Following this, the major claw was extended slowly and flexed quickly to the front with a quick walk toward the side of the major claw, and then the major claw was extended again and circularly swung down to the front (phase B). This waving accompanied vigorous body elevation (bobbing) and back-and-forth sidewise movement. Crabs always kept their ventral surface facing toward the audience during this waving. Approach of a female often elicited the bustling repetition of phase $B$, and in some cases, waving males entered their burrows and the female could follow. Lateral-circular waving was observed frequently in the breeding season, 
but was rarely observed after the breeding season (Fig. 5a). This waving was performed more frequently to female audiences than to male audiences (Wilcoxon's signed rank test; $Z=-2.521 ; p<0.05)$. There was no significant difference between the frequencies of this waving toward resident and burrowless crabs $(Z=-1.120 ; p=0.263)$.

(b) Lateral-flick waving (Fig. 2)

The major claw was whipped laterally toward the audience with quick walking (chasing) toward the audience. This waving generally elicited the escape behavior of the audience. The major claw of the waving male rarely contacted the audience directly. Males occasionally changed their body direction using their burrow as a pivot; the walking legs of their minor claw side were kept hooked on the lip of their burrow while they changed their body direction to point the side of their major claw toward the audience. Lateral-flick waving was observed throughout the observation period and was performed more frequently to resident crabs than to burrowless crabs (Wilcoxon's signed rank test; $\mathrm{Z}=$ $2.827 ; p<0.05)$, and was performed more frequently to males than to females $(Z=-2.198 ; p<0.05)$. This waving was rarely performed to females during the breeding season, but was often performed to audiences of both sexes before and after the breeding season (Fig. 5b). In contrast to other types of waving, lateral-flick waving was observed frequently after the breeding season.

(c) Rapid-vertical waving (Fig. 3) 
The major and minor claws were held around the buccal region, and were repeatedly raised and lowered very rapidly. Females also performed similar waving with both of their small claws. Crabs generally performed this waving at the entrances to their burrows with the walking legs often half concealed in the burrow. When a burrowless crab came nearby, most resident crabs rushed back to their burrows and performed rapid-vertical waving at the entrances to the burrows. This waving was not conspicuous from a distance, but was commonly observed throughout the observation period (Fig. 5c). Rapid-vertical waving was performed more frequently to male audiences than to female audiences (Wilcoxon's signed rank test; $Z=-2.411 ; p<0.05)$, but there was no significant difference between the frequencies of this waving toward resident and burrowless crabs $(Z=-1.433 ; p=0.152)$.

(d) Circular waving (Fig. 4)

The flexed major claw was extended to the side, lifted vertically, and circularly swung down to the front. Compared to the three other types of waving, circular waving was the most conspicuous from a distance. Body elevation was absent or a small elevation occurred when the major claw was lifted up. This waving often accompanied feeding behavior (the minor claw repeatedly brought sediment to the crab's mouth). Except when the crabs changed the feeding site, they rarely walked around or changed body direction during this waving. Circular waving was most frequently observed prior to the breeding season and 
had no obvious audience in most cases (Fig. 5d). This waving was rarely observed after the breeding season. There was no significant difference between the frequencies of this waving toward male and female audiences (Wilcoxon's signed rank test; $Z=-0.944 ; p=0.345$ ) or toward resident and burrowless audiences $(Z=-0.674 ; p=0.500)$.

\section{Discussion}

The four types of claw-waving display found in the present study were discriminated from each other by the motions of the major claw. Additionally, the body motion such as back-and-forth sidewise movement was used to clarify the differences. (1): Lateral-circular waving was incomparably complex display; however, the back-and-forth sidewise movement and quick lateral flexion of a major claw clearly represented this waving. Perhaps the audiences recognize this waving when they visually perceive both faces of the signaler's major claw. (2): Lateral-flick waving was described as simple lateral extensions of the major claw, which was performed only when the audience was at close hand.

Because crabs are quite sensitive to nearby moving things, lateral-flick waving almost exclusively elicits escape behavior of the audience. (3): Rapid-vertical waving was defined by the simple vertical motions of the major claw. From the viewpoint of the audience, this waving would be perceived as blinking color of dorsum manus. (4): Circular waving was defined as the intermittent simple circumduction of the major claw. Unlike lateral-circular waving, this waving does 
not contain back-and-forth sidewise movement or quick lateral flexion of the major claw.

Claw-waving of fiddler crabs has often been explained as a courtship behavior (e.g., Yamaguchi 1983, 2001a; Burford et al. 2000; Pope 2000a, b; Christy et al. 2001, 2002). In the present study, however, circular waving was frequently performed prior to the breeding season (Fig. 5d), and rapid-vertical waving was performed more frequently to male audiences (Fig. 5c), suggesting that these types of waving were not directly related to courtship. By contrast, lateral-circular waving appeared to be used for courtship because this type of waving was observed frequently in the breeding season and was performed more frequently to female audiences (Fig. 5a). Perhaps phase B of lateralcircular waving (quick flexion of the major claw) plays an important role in leading females into burrows, because most males continuously performed this action just before enticing females. Lateral-circular waving, including vigorous body elevation and back-and-forth sidewise movement, would be an energyconsuming display. This waving might therefore be used as a "handicap" that honestly signal competitive ability or quality of the male (see Zahavi 1975).

Several species of fiddler crabs are known to use claw-waving for territorial displays (e.g., Crane 1958; Salmon 1965; Zeil et al. 2006). Territorial displays generally seemed to be performed either to neighbor residents in border disputes or to intruding burrowless crabs to prevent a burrow takeover. Lateralflick waving in the present study may have been performed as part of border disputes against neighboring resident crabs, because this waving was mostly performed to neighbor residents. Although lateral-flick waving may be used in 
border disputes, this waving is not necessary to have the information about signaler's fighting ability. Perhaps this waving can elicit the escape behavior of nearby crabs by driving the sensor that elicits the crab's escape behavior. In $U$. lactea, residents of both sexes defend their territories around their burrows (Yamaguchi \& Tabata 2004). Therefore, females can be the rivals for males in border disputes, especially when they are not receptive to mating. Lateral-flick waving was performed throughout the observation period, but was not performed frequently toward female audiences in the breeding season (Fig. 5b). Males may have performed this aggressive waving toward both sexes of crabs when it was likely that no females were receptive.

Also, rapid-vertical waving seemed to be used as a territorial behavior, but this waving was performed mainly to intruding burrowless males (Fig. 5c). One notable point is that resident females also showed a similar waving pattern at the entrance to their burrows. In the field, there are many burrowless crabs either looking for an empty burrow or attempting to take over a burrow from other crabs (Pope 2005; Zeil et al. 2006). Therefore, residents of both sexes would have to defend their burrows from intruding crabs. Perhaps it is difficult for intruders to steal or rob a burrow from residents when the residents are aware of the intruder. Resident crabs may thus be able to deter intruders by performing rapid-vertical waving when they detect intruding crabs.

In several species, claw-waving is performed in the absence of any specific audience (Crane 1958; Christy et al. 2001; How et al. 2008). Likewise, the circular-waving observed in my study did not have apparent audience in most cases (Fig. 5d). These spontaneous displays may act as "broadcast" signals 
that are performed to a number of unspecified potential audiences (see Martins 1993; How et al. 2008). Because circular waving was conspicuous from a distance, this waving might act as a long-distance courtship signal to attract females from afar. However, why males of $U$. lactea frequently performed circular waving before the breeding season cannot be explained. Another possibility is the advertisement of their competitive abilities. If males can signal their fighting ability by circular waving, this waving would reduce the number of fruitless fights against intruding crabs.

The results of the present study suggest that males of $U$. lactea use at least four distinct types of claw-waving display. One possible reason to use multiple signals is receiver variability (Hebets \& Papaj 2005). Several species of animals use different signals for different types of audience, such as males and females, young and old (Narins \& Capranica 1976; Martins 1993; Coleman et al. 2004). In this case, males may exhibit different aspects of their quality to different types of audiences (see Candolin 2003) because their current condition (such as fighting ability) would be important for rival males, but the genetic quality of waving males would be more important for mate-searching females.

Multiple signaling may also be able to decrease the possibility of misinterpretation. Especially, dissimilarity between courtship and aggressive signals would be important, because intense courtship displays may potentially elicit escape behavior of the mates (Borgia \& Presgraves 1998; Coleman et al. 2004; How et al. 2008). How et al. (2008) showed that males of U. perplexa reduce threatening components of their waving during close-range courtship signaling because these components may frighten females away. As shown 
above, males of $U$. lactea can be aggressive toward females in territorial disputes. If males used distinct signaling in courtship and aggression, matesearching females would be able to approach waving males without anxiety.

Four types of claw-waving display found in the present study appeared to be used in different social contexts. Males may have needed to use several different types of waving in order to transmit different messages. The results suggest that lateral-circular, lateral-flick, and rapid-vertical waving were related to courtship, border dispute, and burrow guarding, respectively. Unlike these waving, it was difficult to deduce the function of circular waving because this waving did not have obvious audiences. The baseline audience of this waving might be specified by manipulating the density and the sex ratio of audiences. Some experimental study will therefore be needed to estimate the function of this waving.

Acknowledgements I am grateful to M. Imafuku, A. Mori, and T. Yamamoto for providing constructive comments for the study, E. Nakajima for revising the English, and many thanks are also due to J. Christy, Y. Henmi, S. Ishida, T. Koga, N. Nakamura, D. S. Pope, S. E. Vincent, K. Wada, S. Yabuta, and T. Yamaguchi for helpful advice. This research was financially supported in part by Global COE Program A06 to Kyoto University. 


\section{References}

Borgia G (1995) Complex male display and female choice in the spotted

bowerbird: specialized functions for different bower decorations. Anim Behav,

49:1291-1301

Borgia G, Presgraves DC (1998) Coevolution of elaborated male display traits in

the spotted bowerbird: an experimental test of the threat reduction hypothesis.

Anim Behav, 56:1121-1128

Burford FRL, McGregor PK, Oliveira RF (2000) Response of fiddler crabs (Uca tangeri) to video playback in the field. Acta Ethol, 3:55-59

Candolin U (2003) The use of multiple cues in mate choice. Biol Rev, 78:575-

595

Chaine AS, Lyon BE (2008) Intrasexual selection on multiple plumage ornaments in the lark bunting. Anim Behav, 76:657-667 
Christy JH, Backwell PRY, Goshima S (2001) The design and production of a sexual signal: hoods and hood building by male fiddler crabs Uca musica.

Behaviour, 138:1065-1083

Christy JH, Backwell PRY, GoshimaS, Kreutera T (2002) Sexual selection for structure building by courting male fiddler crabs: an experimental study of behavioral mechanisms. Behav Ecol, 13:366-374

Coleman SW, Patricelli GL, Borgia G (2004) Variable female preferences drive complex male displays. Nature, 428:742-745

Crane J (1958) Aspects of social behavior in fiddler crabs, with special reference to Uca maracoani (Latreille). Zoologica, 43:113-130

Elias DO, Hebets EA, Hoy RR, Mason AC (2005) Seismic signals are crucial for male mating success in a visual specialist jumping spider (Araneae: Salticidae). Anim Behav, 69:931-938 
Hebets EA, Papaj DR (2005) Complex signal function:developing a framework of testable hypotheses. Behav Ecol Sociobiol, 57:197-214

How MJ, Zeil J, Hemmi JM (2007) Differences in context and function of two distinct waving displays in the fiddler crab, Uca perplexa (Decapoda:

Ocypodidae). Behav Ecol Sociobiol, 62:137-148

How MJ, Hemmi JM, Zeil J, Peters R (2008) Claw waving display changes with receiver distance in fiddler crabs, Uca perplexa. Anim Behav, 75:1015-1022

Martins EP (1993) Contextual use of the push-up display by the sagebrush lizard, Sceloporus graciosus. Anim Behav, 45:25-36

Narins PM, Capranica RR (1976) Sexual differences in auditorysystem of tree frog Eleutherodactylus coqui. Science, 192:378-380

Pope DS (2000a) Video playback experiments testing the function of claw waving in the sand fiddler crab. Behaviour, 137:1349-1360 
Pope DS (2000b) Testing function of fiddler crab claw waving by manipulating social context. Behav Ecol Sociobiol, 47:432-437

Pope DS (2005) Waving in a crowd: fiddler crabs signal in networks. In:

McGregor PK (ed) Animal communication networks. Cambridge University

Press, Cambridge, pp 247-262

Salmon M (1965) Waving display and sound production in the courtship

behavior of Uca pugilator, with comparisons to U. mimax and U. pugnax.

Zoologica, 50:123-150

Severinghaus LL, Lin HC (1990) The reproductive behaviour and mate choice of the fiddler crab (Uca lactea lactea) in mid-Taiwan. Behaviour, 113:292-308

Yamaguchi T (1983) Representative shore animals in the Amakusa Islands (1)

The fiddler crab, Uca lactea lactea (De Haan). Calanus, 8:25-32 
Yamaguchi T (2001a) The mating system of the fiddler crab, Uca lactea

(Decapoda, Brachyura, Ocypodidae). Crustaceana, 74:389-399

Yamaguchi T (2001b) The breeding period of the fiddler crab, Uca lactea

(Decapoda, Brachyura, Ocypodidae). Crustaceana, 74:285-293

Yamaguchi T, Tabata S (2004) Territory usage and defence of the fiddler crab,

Uca lactea (De Haan) (Decapoda, Brachyura, Ocypodidae). Crustaceana, $77: 1055-1080$

Zahavi A (1975) Mate selection - a selection for a handicap. Journal of Theoretical Biology, 53:205-214

Zeil J, Hemmi JM, Backwell PRY (2006) Fiddler crabs. Curr Biol, 16:40-41 


\section{Figure legends}

Fig. 1. Lateral-circular waving of male $U$. lactea. A male (center) beside his burrow is performing lateral-circular waving toward a burrowless female (top).

The video is available at: http//www.momo-p.com/showdetail-

e.php?movieid=momo091127ul01a

Fig. 2. Lateral-flick waving of male $U$. lactea. A male (moving from bottom to center) beside his burrow is performing lateral-flick waving toward a burrowless male (moving from center to top). The video is available at: http//www.momop.com/showdetail-e.php?movieid=momo091127ul02a

Fig. 3. Rapid-vertical waving of male $U$. lactea. A male (lower-right) is performing rapid-vertical waving toward a burrowless male (center). The video is available at: http//www.momo-p.com/showdetaile.php?movieid=momo091127ul03a 
Fig. 4. Circular waving of male $U$. lactea. A male (center) is performing circular waving along with feeding behavior. There is no obvious audience. The video is available at: http//www.momo-p.com/showdetaile.php?movieid=momo091127ul04a

Fig. 5. Seasonal fluctuation pattern of the frequencies of claw-waving and its audience in male $U$. lactea. Each bar shows the mean frequency of the display per minute within a single spring tide. (a) Lateral-circular waving; (b) Lateralflick waving; (c) Rapid-vertical waving; (d) Circular waving. 
